\title{
Review of Malawey, Victoria, A Blaze of Light in Every Word: Analyzing the Popular Singing Voice (Oxford University Press, 2020)
}

\author{
Michèle Duguay
}

NOTE: The examples for the (text-only) PDF version of this item are available online at: https://www.mtosmt.org/issues/mto.21.27.2/mto.21.27.2.duguay.php

KEYWORDS: voice, popular music, timbre, prosody, technological mediation, pitch, vocal quality, Elliott Smith

Received December 2020

Volume 27, Number 2, June 2021

Copyright (๑) 2021 Society for Music Theory

[1] The voice is one of popular music's most salient aspects. Listening to a voice, Miriama Young writes, "[invites us] to hear another's voice with our own body, in relation to our own" $(2015,3)$. Despite its prominent role, vocality remains an elusive object of analysis. What parameters of the voice-timbre, pitch, rhythm, lyrical content-should one analyze? How should these parameters be analyzed? Moreover, how can an analyst successfully account for each voice's individuality, while relying on a theoretical framework that is general enough to enable comparisons and abstractions?

[2] In order to address these questions, A Blaze of Light in Every Word proposes a conceptual model for analyzing the popular singing voice. Expanding on her previous work on vocality $(2007,2010$, 2014), Victoria Malawey grants the voice the same sophisticated level of analytical attention that has been given to parameters such as pitch, harmony, and rhythm. Her model allows her to describe the affective and physiological aspects of recorded performances in detail; moreover, throughout the book, she uses her model to highlight the different ways that vocal delivery can evoke "cultural, gender, social, and racial identities" (29).

[3] One of the book's most significant contributions lies in its synthesis of ideas propounded in recent literature. Malawey draws, for instance, on Kate Heidemann's recent scholarship on vocal timbre and embodiment (2016), Allan Moore's exploration of meaning in popular music (2012), and Jean Callaghan's studies on the physicality of the voice (2000). By consolidating decades of work and calling for a serious engagement with the singing voice, Malawey solidifies vocal analysis as a valuable subfield of inquiry within music studies.

[4] While Malawey's object of study is the sonic materiality of the voice - the tangible, physiological, and acoustic aspects of a sung vocal performance - the book opens with an overview of philosophically oriented branches of voice studies. The introductory chapter surveys, among other ideas, notions of voice as embodiment and "grain" (Barthes 1985, Frith 1996), voice as intention (Cone 1974), and voice as metaphor for agency and power (Dunn and Jones 1994, 
Feldman 2015). The section could serve as a useful literature review that might be assigned in a course on voice or sound studies.

[5] Malawey's conceptual model is depicted in Example 1. The model is divided into three overlapping zones - pitch, prosody, and quality - which are respectively addressed in Chapters 2, 3, and 4. "Pitch" encompasses a variety of parameters, including intonation, register, and types of vocal delivery. "Prosody," which Malawey defines as "the pacing and flow of delivery" (69), includes phrasing, metric placement, motility (an artist's capacity for fluid and agile singing), embellishment, and consonantal articulation. The chapter on "quality" examines timbre insofar as it imparts "the feelings, emotions, and meanings that listeners ascribe to the recordings and performances they consume" (94). Since Malawey studies recorded performances, her analyses also consider the ways in which voices are technologically processed before reaching a listener. This overlapping area at the center of the Example 1, "mediation with technology," is addressed in Chapter 5. Chapters 2 through 5 follow similar structures: each summarizes the existing literature on the parameter under study, defines relevant terms, and finally puts the model into practice by analyzing aspects of vocal performance in covers of popular songs. ${ }^{(1)}$ The sixth chapter considers all aspects of the conceptual model of Example 1 through analyses of vocal performances by Elliott Smith.

[7] Chapter 2 delves into the intricacies of vocal pitch by analyzing different covers of Leonard Cohen's "Hallelujah" (1984), including versions by Jeff Buckley (1994), Rufus Wainwright (2001), k. d. lang (2004), Imogen Heap (2006), Alexandra Burke (2008), and Kate McKinnon (2016). Her prosebased analyses are supported by transcriptions of vocal melodies and spectrograms. The latter can be used to compare the overtone activity between a singer's chest voice and head voice. Malawey uses such "close readings" of the voice in order to highlight linkages between pitch parameters and listeners' perception of the vocalists' identity. Consider, for instance, her discussion of intonation in the various "Hallelujah" covers. First, she analyzes Cohen's speech-like delivery in light of Adriana Cavarero's observation that song is socially constructed as "naturally feminine" and speech as "naturally masculine" $(2005,118)$. Given this association, Malawey argues that when male artists use speech-like delivery, the effect is unmarked and commonplace. When women adopt a speechlike delivery, conversely, it is more likely to be read by listeners as expressing a "specific emotive effect" (35). Cohen's use of a "masculine" vocal delivery in "Hallelujah," then, "reinscribe[s his] identity as sincere, authentic, or genuine" because it seems to reinforce his male identity (36). The notion of authenticity returns in Malawey's analysis of intonation in McKinnon's rendition of the song on Saturday Night Live on November 12, 2016, days after Cohen's death. McKinnon performed the song as Hillary Clinton, who had recently lost the American presidential election to Donald Trump. McKinnon's untrained voice, perceived as amateurish because of its imprecise intonation, allows her performance to be perceived as an unfiltered and authentic display of emotion that contrasts with her usual comic appearances on the television show.

[8] In the third chapter, Malawey distinguishes between three interrelated levels of prosody: prosody as a marker of genre or style, prosody as an artist's individual mode of delivery, and prosody as a song-specific feature. Her analyses center on different covers of Justin Timberlake's 2002 song "Cry Me a River." In discussing phrasing, she compares the "clipped, segmented style" of Timberlake's version (Example 2) with The Cliks' more flowing cover (Example 3). Malawey understands the choppier phrasing and background vocals of Timberlake's rendition as evocative of "a shared experience to commiseration through heartbreak" (74). The Cliks' smoother phrase connectivity evokes, for Malawey, a more individual expression of distress. Central to her analysis, again, is the overarching goal to link vocal materiality to listeners' perception of emotion and identity.

[9] Such interpretations of a voice's meaning are by default subjective and contextual. In another song, with different lyrics and performers, a segmented prosody may point towards a different experience. This observation speaks to a broader methodological issue: to what extent is it possible to map musical material onto cultural associations? Another example of the difficulties that arise when trying to directly link sound to notions of identity can be observed in Malawey's summary of the affective effects of vibrato. She writes, "Critics and scholars associate a wide range of 
sometimes conflicting emotive effects with vibrato, including power, intensity, and increasing control ... heightened emotionality and loss of control . . f femininity, indecisiveness, or alternatively as a 'form of resistance' against negative gendered associations ... naturalness and ease ... mournfulness and grief . . lack of vibrato may suggest effects of 'effortlessness' and 'emotional distance'" (38). This excerpt exemplifies the difficulties awaiting analysts wishing to explore extra-musical associations. It is virtually impossible-and indeed, not necessarily desirable - to generalize the ways in which a specific musical parameter such as vibrato, phrase length, or distortion may evoke emotional states or identity markers.

[10] Malawey is aware of this issue and does not purport to provide a generalized theory of voice/identity relationships. In order to avoid painting in overly broad strokes, her discussions of voice and identity are carefully presented as context-specific. Throughout A Blaze of Light, she frequently cautions the reader against essentialist conclusions built on the premise that identity categories have innate and fixed characteristics that are revealed through the voice. ${ }^{(2)}$ Analysts should avoid generalizing statements implying that particular modes of vocality - timbre and range, for instance-automatically map onto specific identity categories. While analysts can tie a singer's voice to their gender identity, for instance, any association between voice and identity should be critically examined as a culturally specific construction. Malawey therefore approaches associations between voice and identity on a case-by-case basis, while still acknowledging the way that listeners attribute certain vocal characteristics to identity based on dominant cultural narratives. In her discussion of Leonard Cohen, for instance, she does not imply that his voice is an innate manifestation of an essential masculinity. She instead highlights how listeners might hear Cohen's voice as masculine based on the common association between a deep voice and masculinity.

[11] The fourth chapter addresses vocal quality. Drawing on Cornelius Reid's notion of sonance, defined as "the aural sum of the physical properties of vocal tone" (1983, 349), Malawey surveys the physical characteristics of the voice, along with the different ways in which they can express emotional states. She does not aim to establish rigid links between vocal qualities and specific emotions, but rather presents the reader with brief literature reviews on the various - and sometimes contrasting - extra-musical associations that have been ascribed to certain aspects of vocal quality. She notes, for instance, that pressed phonation, which indicates insufficient airflow, has been characterized as evocative of tension, aggression, repression, anguish, stress, or scorn (102). Vocal roughness, harshness, and growls have been associated with aggression, dominance, and male sexual prowess. In a remarkable analytical vignette, Malawey builds on comments from different YouTube video performances of the song "Still" by the lead vocalist of The Cliks, transgender man Lucas Silveira $(2010,2013)$, to describe the perceived eroticism of his voice. She shows that fans enthusiastically reacted to the vocal changes brought on by Silveira's hormone therapy, ascribing sexiness and other extra-musical associations to his voice's raspiness and narrowing range.

[12] Studies of vocality, which is often understood within essentialist frameworks of gender, run the risk of exclusively relying on gender binarism and cis-gender experiences. Malawey's analytical focus on the voices of transgender and non-binary singers is therefore commendable. ${ }^{(3)}$ In the second chapter, for instance, she provides an in-depth discussion of the role of pitch and tessitura in the voices of transgender singers, examining, for instance, the physiological changes that a vocalist might experience when undergoing testosterone therapy. Malawey pushes back against the frequent use of terms such as "trans-sexual" (Poizat 1991), "transgender" (Halberstam 2005), or "cross-singing" (Mungen 2006) to refer to the voices of cis-gender musicians, because such qualifications ignore the voices of transgender musicians. In other words, describing a cis-gender man's use of falsetto as a "transgender" mode of vocal expression - no matter how gendersubversive the performance-erases and renders invisible the voices of transgender singers. Moreover, these qualifiers leave little to no room for exploring genderqueer and non-binary vocalities. Malawey proposes the term "transvocality" to refer to the vocal materiality of trans singers, and suggests that gender-subversive performances - falsetto, pitch shifting, and so on - by cis-gender musicians should be referred to as "genderbending." In addition to this welcome terminological update, Malawey frequently provides analyses of vocal performances by 
transgender singers. The book contains many analytical vignettes on Silveira, as well as on singersongwriter Namoli Brennet, who transitioned after puberty. Malawey surmises that Brennet "sings in a deliberately breathy tone ... to create a vocal tone suitable to her gender identity" (100), since breathiness is marked as female for many listeners (Dibben 2009; Burns, Lafrance, and Hawley 2008; Boak 2015). Malawey acknowledges that the link between breathiness and femininity is culturally constructed but stops short from unpacking the origins and implications of this association. While she notes that breathiness can evoke physical intimacy and sexual desire, she does not explore why listeners may link these notions to femininity. A deeper look into the links between voice and identity frequently made by listeners would have been an effective opportunity for Malawey to further critique the way gender is constructed in popular music vocalities.

[13] The fifth chapter addresses the impact of technology on the recorded voice and the ways in which the use of technology may connote various meanings. The effects studied include pitch effects (Auto-Tune and other forms of digital pitch modification), alterations of timbre (compression and distortion), and prosodic effects that have an impact on phrasing, flow, and the pacing of events (delay, layering, and panning). Malawey proposes a spectrum that ranges between "wet" and "dry" technological mediation. A "wet" process-such as extreme distortionmakes audible the use of technology, while a "dry" process - such as the subtle use of pitch correction - creates a sound that suggests an acoustic, unmediated listening experience. ${ }^{(4)}$ The wet/dry spectrum allows Malawey to explore how listeners may interpret technological mediation through the longstanding binary between technology and nature. ${ }^{(5)}$ Technological mediation is used in contrasting ways, for instance, in Björk's "Hunter" and its cover by Kaitlyn Ni Donovan (2004). As shown in Example 4, Björk uses a mixture of wet and dry processes in subsections of "Hunter." These contrasts help delineate the form of the song - the chorus, for instance, features especially stark contrasts between both types of mediation-while creating a sense of textural intensification. By contrast, Ni Donovan's version features dry technological processes - no backing vocals, no obvious filtering, and no vocal layering - that create a more "straightforward storytelling experience" (143).

[14] In the final Chapter, Malawey synthesizes all the components of her conceptual model through analyses of Elliott Smith's songs "Roman Candle" (1994), “Between the Bars" (1997), and "Twilight" (2004). By comparing Smith's original songs to their covers by Seth Avett and Jessica Lea Mayfield (2015), she aims to explain the compelling sense of "longing or desperation" evoked by Smith's voice (147). Malawey surveys each song's range, tessitura, registration, pitch bends, phrasing, rhythmic articulation, consonantal articulation, and qualitative aspects "such as greater twang in Mayfield's delivery and greater nasality in Smith's" (149). She also considers technological mediation, noting that Smith's overdubbed unison vocals evoke loneliness, in contrast with Avett and Mayfield's harmonies. Ultimately, Malawey shows that the unique quality of Smith's voice cannot effectively be conveyed by other singers, reminding the reader that the individuality of each voice is responsible for the ineffable aspects of musical performance.

[15] Throughout the final chapter, Malawey's enthusiasm for Smith's vocal performance is palpable. Rather than positioning herself as an objective observer, she describes the aspects of vocal materiality that prompt her strong emotional response to the recording. By reporting her subjective reactions to these vocal performances, Malawey opens up space for further theorization on the concept of the listener. ${ }^{(6)}$ Who, exactly, is the listener in our musical analyses? How can we account for the individuality of listeners, each of whom brings specific biases, experiences, and impressions to a musical encounter? Malawey asserts that as listeners, we often make "subconscious assessments of a singer's identity (race, gender, socioeconomic standing, geographic location, nationality, age, and so forth) and correlate certain vocal characteristics with these aspects of identity" (97). These responses are not universal: a listener's own identity and experience must affect these subconscious assessments. A Blaze of Light therefore invites an in-depth exploration into the ways in which a listener's individual standpoint shapes musical meaning.

[16] A Blaze of Light is a valuable addition to the field of music theory and analysis. Malawey combines various bodies of scholarship while proposing an original model for understanding and analyzing the sound of the singing voice. Because of its engaging tone, clear explanation of 
complex parameters, and thorough survey of literature, the book will be a helpful pedagogical resource. While Malawey admirably unpacks the intricacies of voice, gender, and sexuality, the racialized dimensions of vocality are given less attention. I hope to see future scholarship use her book as a springboard for further analyses on race and voice.

[17] In her recent call for an antiracist and feminist music theory, Alissandra Reed stressed the importance of "new tools and new canons or no canons at all" (2020). Malawey provides a new tool, one that she puts into practice to explore relationships between sound and identity. This method will surely be extended - by Malawey herself and by others - to additional voice-based musical repertoires. As mentioned earlier, scholars might also take the proposed linkages between sound and identity as a starting point to theorize the complex network of relationships between voice, performer, and listener. Finally, music information retrieval (MIR) tools and techniques could be instrumental for exploring the parameters encompassed by Malawey's model. In addition to spectrograms, other measurements enabled by MIR (such as F0 estimation, spectral centroid, and RMS energy) may be useful in analyzing vocal materiality. ${ }^{(7)}$ Malawey's book is a timely intervention, one that both consolidates recent analytical studies on voice and proposes an analytical framework with far-reaching implications within popular music studies.

Michèle Duguay

The Graduate Center, City University of New York

365 5th Ave.

New York, NY 10016

mduguay@gradcenter.cuny.edu

\section{Works Cited}

Baitz, Dana. 2018. “Towards a Trans* Method in Musicology." In The Oxford Handbook of Music and Queerness, edited by Fred Everett Maus and Sheila Whiteley. Oxford University Press. https://doi.org/10.1093/oxfordhb/9780199793525.001.0001.

Barthes, Roland. 1985. Responsibility of Forms. Translated by Richard Howard. University of California Press.

Boak, Sarah. 2015. "Phono-somatics: Gender, Embodiment, and Voice in the Recorded Music of Tori Amos, Björk, and PJ Harvey." Ph.D. dissertation, University of Southampton.

Brøvig-Hanssen, Ragnild and Anne Danielsen. 2016. Digital Signatures: The Impact of Digitization on Popular Music Sound. The MIT Press.

Burns, Lori, Marc Lafrance, and Laura Hawley. 2008. "Embodied Subjectivities in the Lyrical and Musical Expression of PJ Harvey and Björk." Music Theory Online 14 (4). https://mtosmt.org/issues/mto.08.14.4/mto.08.14.4.burns_lafrance_hawley.html.

Callaghan, Jean. 2000. Singing and Voice Science. Singular Publishing Group.

Cavarero, Adriana. 2005. For More Than One Voice: Toward a Philosophy of Vocal Expression. Translated by Paul A. Kottman. Stanford University Press.

Cone, Edward T. 1974. The Composer's Voice. University of California Press.

Cox, Arnie. 2016. Music and Embodied Cognition: Listening, Moving, Feeling, and Thinking. Indiana University Press.

DeMan, Brecht, Kirk McNally, and Joshua D. Reiss. 2017. "Perceptual Evaluation and Analysis of Reverberation in Multitrack Music Production." AES: Journal of the Audio Engineering Society 65 (12): 108-16. https://doi.org/10.17743/jaes.2016.0062.

Devaney, Johanna. 2016. "Inter- Versus Intra-Singer Similarity and Variation in Vocal Performances." Journal of New Music Research 45 (3): 252-64. https://doi.org/10.1080/09298215.2016.1205631. 
Dibben, Nicola. 2009. Björk. Indiana University Press.

Dunn, Leslie C., and Nancy A. Jones. 1994. “Introduction.” In Embodied Voices: Representing Female Vocality in Western Culture, edited by Leslie C. Dunn and Nancy A. Jones, 1-13. Cambridge University Press.

Eidsheim, Nina Sun. 2019. The Race of Sound: Listening, Timbre, and Vocality in African American Music. Duke University Press.

Feldman, Martha. 2015. “The Interstitial Voice: An Opening." In “Colloquy: Why Voice Now?,” convened by Martha Feldman. Journal of the American Musicological Society 68 (3): 653-59. https://doi.org/10.1525/jams.2015.68.3.653.

Frith, Simon. 1996. Performing Rites: On the Value of Popular Music. Harvard University Press.

Halberstam, Jack. 2005. In a Queer Time and Place: Transgender Bodies, Subcultural Lives. New York University Press.

Hardman, Kristi. Forthcoming. “The Continua of Sound Qualities for Tanya Tagaq's Katajjaq Sounds." In Trends in World Music Analysis, vol. 1, edited by Noé Dinnerstein, Sam Mukherji, and Lawrence Shuster. Routledge.

Heidemann, Kate. 2014. “Hearing Women's Voices in Popular Song: Analyzing Sound and Identity in Country and Soul." Ph.D. dissertation, Columbia University.

_ 2016. "A System for Describing Vocal Timbre in Popular Song." Music Theory Online 22 (1). https://www.mtosmt.org/issues/mto.16.22.1/mto.16.22.1.heidemann.html.

James, Robin. 2020. "Music and Feminism in the 21st Century." Music Research Annual 1: 1-25. https://musicresearchannual.org/vol-1-20-james-music-and-feminism/.

Luong, Vivian. 2017. “Rethinking Music Loving." Music Theory Online 23 (2). https://mtosmt.org/issues/mto.17.23.2/mto.17.23.2.luong.html.

Malawey, Victoria. 2007. “Temporal Process, Repetition, and Voice in Björk's Medúlla.” Ph.D. dissertation, Indiana University.

2010. "An Analytic Model for Examining Cover Songs and Their Sources." In Pop-Culture Pedagogy in the Music Classroom: Teaching Tools from American Idol to YouTube, edited by Nicole Biamonte, 203-32. Scarecrow Press.

2014. “'Find Out What It Means to Me': Aretha Franklin's Gendered Re-Authoring of Otis Redding's ‘Respect'.” Popular Music 33 (2): 185-207.

Moore, Allan F. 2012. Song Means: Analysing and Interpreting Recorded Popular Song. Ashgate.

Mungen, Anno. 2006. "'Anders als die Anderen,' or Queering the Song." In Queering the Popular Pitch, edited by Sheila Whiteley and Jennifer Rycenga, 67-80. Routledge.

Poizat, Michel. 1991. "'The Blue Note' and 'The Objectified Voice and the Vocal Object'." Cambridge Opera Journal 3 (3): 199-211.

Reed, Alissandra. 2020. “Who Does Your Scholarship Serve? Or, The Music Theorists' Guide to NonViolent Scholarship." Project Spectrum's Keynote Address, "After 'Reframing Music Theory': Doing the Work." Presented at the Music Theory Society of New York State 49th annual meeting.

Reid, Cornelius. 1983. A Dictionary of Vocal Terminology: An Analysis. Joseph Patelson Music House.

Robinson, Dylan. 2020. Hungry Listening: Resonant Theory for Indigenous Sound Studies. University of Minnesota Press.

Straus, Joseph N. 2011. Extraordinary Measures: Disability in Music. Oxford University Press. 


\section{Footnotes}

1. The performances studied in the book draw from various post-1980s popular Anglophone repertoires, with a focus on the music of singer-songwriters such as Björk, Elliott Smith, and Leonard Cohen and "Top 40" songs by Lady Gaga, Justin Timberlake, and Mariah Carey.

Return to text

2. This assertion evokes recent scholarship by Nina Sun Eidsheim (2019), whose book The Race of Sound encourages readers to examine the racialized and gendered expectations they bring to their listening practice.

Return to text

3. For an overview of recent trends in music scholarship and trans studies, see Baitz (2018) and James (2020).

Return to text

4. Malawey notes that while dry sounds convey a "natural" impression, every recorded performance is mediated through technology. Relatedly, Brøvig-Hanssen and Danielsen note that "pure" or "natural" sounding vocals, while they may aurally suggest an unmediated recording, are in fact "highly processed according to the conventions of pop song technology" $(2016,132)$.

Return to text

5. Malawey's theoretical framing seamlessly maps onto Brøvig-Hanssen and Danielsen's concept of opaque and transparent technological mediation (2016).

Return to text

6. Straus (2011), Heidemann (2014), Cox (2016), Luong (2017), and Robinson (2020) take different theoretical approaches to the concepts of "listener" and "analyst-listener."

Return to text

7. Such projects would be positioned within an evolving subfield of music studies that uses audio feature extraction and digital methods to analyze recorded musical performance (Devaney 2016; DeMan, McNally, and Reiss 2017; Hardman Forthcoming).

Return to text

\section{Copyright Statement}

Copyright $\odot 2021$ by the Society for Music Theory. All rights reserved.

[1] Copyrights for individual items published in Music Theory Online (MTO) are held by their authors. Items appearing in MTO may be saved and stored in electronic or paper form, and may be shared among individuals for purposes of scholarly research or discussion, but may not be republished in any form, electronic or print, without prior, written permission from the author(s), and advance notification of the editors of MTO.

[2] Any redistributed form of items published in MTO must include the following information in a form appropriate to the medium in which the items are to appear:

This item appeared in Music Theory Online in [VOLUME \#, ISSUE \#] on [DAY/MONTH/YEAR]. It was

authored by [FULL NAME, EMAIL ADDRESS], with whose written permission it is reprinted here.

[3] Libraries may archive issues of MTO in electronic or paper form for public access so long as each issue is stored in its entirety, and no access fee is charged. Exceptions to these requirements must be approved in writing by the editors of $M T O$, who will act in accordance with the decisions of the Society for Music Theory.

This document and all portions thereof are protected by U.S. and international copyright laws. Material contained herein may be copied and/or distributed for research purposes only. 
